\title{
Research on the Mode of Cultivating Innovative Talents among Undergraduate Students Majoring in Mechanical Engineering
}

\author{
De-hai Zhang, Yan-qin Li, Yu Ma, Ying Gui, Jian-xiu Liu \\ Mechanical and Electrical Engineering Institute \\ Zhengzhou University of Light Industry \\ Zhengzhou City, People's Republic of China \\ zhangdehai0318@163.com
}

\begin{abstract}
Through the analysis of the present situation of college mechanical engineering education in China and existing studies from other countries, we construct a platform for the innovation training program by universities and enterprises for undergraduate students in mechanical engineering. This platform integrates on-campus practices, off-campus practices and three production practices. This research provides a practical learning platform for students from multi-domains and multi-levels, which is composed of off-campus production-based practice base, on-campus laboratory activities and schoolenterprise joint research and development center. The aim is to improve students ' practice and innovation capabilities, to achieve the multi-win situation for students, universities and enterprises, and to increase innovation ability of college students.
\end{abstract}

Keywords-Mechanical engineering major; School-enterprise cooperation association; Innovation; Mechanical engineering

\section{INTRODUCTION}

The concept of innovation was first proposed by the economist Joseph Schumpeter when he introduced science and technology into the production system. Schumpeter believed that "innovation" is an economic category and non-technical category; it not only refers to the invention in science and technology, and proposed that "innovation" represents the introduction of science and technology into the enterprise, to form a new kind of production capacity [1]. In other words, "innovation" is to introduce a new combination of production factors and production conditions into the production system, namely 'to establish a new production function", with an aim of obtaining potential profits.

In 2013, the International Commission on Education for the 21st Century submitted a report entitled "Relationship between Education and Deposits" to UNESCO. It pointed out:" In the world with rapid change driven by social and economic reform, it is possible to value imagination and creativity more," In China, Chinese leader Deng Xiaoping proposed 'Three Orientations' for the Chinese education system and President Jinxing-Xi pointed out that "innovation is the soul of a nation's progress and the force that drives economic development of a nation.” These education views shed light on the reform of higher education in China as follows: universities should not merely impart knowledge, but carry out all-round quality improvement for college students [2]. Universities should be at the forefront of the development of knowledge, in order to explore new knowledge and create new ideas. Universities are suggested to provide students with humanities education and general education, and to conduct knowledge penetration and application on the student, so as to increase the ability of solving practical problems. Talent training mode reform is the key to teaching reform with the purpose of making the student individuality achieve full development, and have the ability of well integrating knowledge, ability and quality. By doing so, college students' qualities in terms of humanities, and science, as well as innovation spirit and practical ability can be improved in training to meet the demands of innovative spirit, practice ability, high-quality innovative talent required by modernization construction in China [3]. College students' innovation ability in China remains to be largely improved. The cultivation of innovation spirit and ability as the key of innovation education has to meet the challenge of knowledge economy, for promoting the needs of economic development of science and technology and improving comprehensive national strength, and education in China for a long run. However their training is performed without taking the necessary innovative training countermeasures [4].

Zhengzhou University of Light Industry is one of the first universities in China to carry out applicationoriented talents' cultivation at undergraduate level of higher education in the major of light industry, which has the right to grant undergraduate degree. Mechanical and Electrical Engineering Institute in Zhengzhou University of Light Industry is listed in provincial key discipline.

\section{RESEARCH STATUS AND EXISTING PROBLEMS}

\section{A. Research Status}

1) Lack of creative consciousness, lack of self-confidence, not good at making full use of and actively creating conditions

Professional mechanical college students in China are characterized by their lack of necessary education innovation enlightenment and being influenced by traditional cultures and 
thoughts, as well as receiving long term exam-oriented education. In addition, teachers in universities pay less attention to inspire and guide, cultivate the students, which make students have less individuality and confidence, and lack of spirit of adventure and innovative consciousness, as well as poor initiative [5-7].

2) Poor innovation knowledge and inability in mastering the knowledge of latest development of this discipline

Mechanical engineering major in different colleges and universities is set up in a closed "ivory tower", where students are exposed to pure knowledge. Under such context, students fail to recognize the future value of knowledge and show lack of innovation initiative.

\section{3) Lack of innovation awareness}

The backward teaching ideas and the shortage of innovation orientated teaching methods, make college students in China get used to follow study rather than practices and innovation; moreover, "cramming" education makes students more rely on the teacher's knowledge, consequently causing students to have a single-, linear thinking mode, and to fail to comprehensively consider and deal with problems.

\section{4) Poor innovation results and innovation skills}

As universities are usually under great pressure in school running, and aged facilities, they therefore endow students with less opportunity to apply the theory into practice; additionally, the scientific research of college students is often conducted in a narrow range, which is unfavorable for students to improve students' innovation ability and achievement.

\section{5) There is no authoritative textbook system}

Western countries have developed some popular textbooks for students majoring in mechanical engineering, forming a relatively mature teaching method and teaching evaluation standard, however little efforts has been made in China in the development of authoritative textbooks. Some colleges and universities that have opened undergraduate students' innovative education courses also exhibit great limitations when selecting textbooks. Education is still in its infancy, and there are no systematic and perfect innovation education theory and culture systems. Thus, education mode is urgent to be perfected and deepened in practice. Innovation orientated education has a long way to go.

\section{B. Existing Questions}

1) Experiments, practice, course design and practical teaching are basic knowledge. The students are trained morely through verification and repetition, lacking experimental technology, and having poor capabilities of design of experiment, experimenter; method and independent work, so it is difficult to make them develop innovation experiment ability

2) At present, most of the industry-university-research cooperation is limited to teachers, which only offer a few opportunities for few students to participate in.

3) Experimental teaching, production practice, curriculum design and research in development center of industryuniversity-research, are characterized bynon-cooperation development.
III. JOINT ESTABLISHMENT OF THE SCHOOL-ENTERPRISE INNOVATION COOPERATION MANAGEMENT ORGANIZATION

In order to well ensure the school cooperation, we have established the practical teaching management team in the form of school-enterprise cooperation association between the joint training and innovation enterprises.

\section{A. Joint formulation of the innovation talent training plan}

In order to promote the innovation awareness, the school, has carried out the training of students in the relevant specialized knowledge in advance for catering to the needs of the enterprise, and implementing the plans so as to meet social demands and to avoid the aimless cultivation of talents.

\section{B. Implementation of excellent engineer plan}

Advanced mode of production requires versatile employees who are able to flexibly tackle problems and have high-quality creative ability. To cater to this need, outstanding engineers plan can be designed and submitted to the Ministry of Education of China, for their approval. Then the plan needs to be implemented after professional teaching steering committee and innovation management team make negotiation and discussion on various aspects concerning present educational system, teaching contents, more practices in mechanical engineer training.

\section{Joint development of new curriculum and teaching materials}

In order to make ensure that the courses of the university reflect the current mainstream technology and the practicability of knowledge, we should develop new teaching materials to adapt to the universities' mechanical reform.

\section{Establishment of the supervision mechanism of practical teaching, and joint quality education of students}

Teachers conscientiously carry out training guidance and strict assessment. In conventional examinations that focus on pure theory. Newly joint mechanism for education of students should be jointly evaluated by the enterprise leaders, actual training master and school tutors to assess the overall performance of the student.

\section{E. Jointly setting up the graduate employment platform and realizing the "zero distance" employment of graduates.}

School-enterprise cooperation and the combination of production and education can run together to train qualified personnel and effectively cope with the problems of mechanical engineering major. The aims include serving China's economic construction, catering to the needs of enterprise, focusing on cultivating students' innovative skills in teaching, and actively carrying out the employment orientated education and training between enterprises, making graduates' capability comply with the market, realizing the satisfaction of schools, enterprises and students, and achieving the goal of inspiring people's satisfaction with higher education. Conclusion 
Based on analysis of the present education status of mechanical engineering major in Chinese colleges and universities and experience of other countries' achievements, joint undergraduate innovation among higher vocational colleges are suggested to develop the research content and platform construction, and integrate on-campus practices (experiment, curriculum design), off-campus practice internship (production) and practical production. Against industry background of the Central Plains Economic Zone in China, universities can construct learning mode, promote practice and innovation design, implement universityenterprise joint research, and establish relevant development centers. By doing so, enterprises, schools, teachers and students are able to achieve multi-win situation, and the understanding between students and enterprises can be enhanced. Furthermore, the purposes of extending students' employment channels, increasing students' employment, and helping enterprises to select talents, developing talent and stabilizing talent team can also be realized. Moreover, practice and innovation ability the innovation ability of college students can be improved.

\section{ACKNOWLEDGEMENT}

The authors would like to express their sincere thanks to Prof. J Liang and C Guo from Xi'an Jiaotong University, for their helpful guidance and valuable suggestions on the experiments. The work was supported by State Key Laboratory for Manufacturing Systems Engineering (Xi'an Jiaotong University) [Grant No. sklms2015012], the Key Laboratory of Advanced Manufacturing technology, Ministry of Education
[Grant No. XDKFJJ[2016]07], the Key Scientific Research Project of Henan Province [Grant No.142102110151], and the Doctoral Program of Zhengzhou University of Light Industry.

\section{REFERENCES}

[1] D. H. Zhang, Y. Q. Li, L. W. Wang, J. X. Liu, H. Li, E. W. Su and Y. Yang, "Research on the quality of teacher training in applied talents colleges with characteristics of light industrial machinery", Henan science and technology, vol. A6, pp. 269-270, June 2014.

[2] D. H. Zhang, Y. Q. Li and D. Q. Zhang, "The application of excellent teaching methods in the teaching of undergraduate colleges", Heilongjiang shizhi, vol. A 23, pp. 280-281, July 2013.

[3] D. H. Zhang, "The analysis of the phenomenon of education in engineering institutions", Shanxi technology, vol. A27, pp. 14-16, April 2012.

[4] J. B. Liu, G. Y. Cui, Y.Q. Li, D. P. Bai and D. H. Zhang, "A brief analysis on how to implement professional teaching staff in engineering colleges education", Shanxi science and technology, vol. A28, pp. 71-74, May 2013.

[5] D. P. Bai, J. Ding, H. J. Duan, J. B. Liu and D. H. Zhang, "The application of project teaching method in the teaching of computer drawing AutoCAD", Science and technology intelligence development and economy, vol. A19, pp. 127-132, December 2013.

[6] D. H. Zhang, J. Liang, C. Guo, Z. X. Chen, "Integrated precision evaluation method for 3D optical measurement system," P I Mech Eng B J Eng Manu, vol 225, pp. 909-920, June 2011.

[7] D. H. Zhang, D. P. Bai, C. Wu, L. W. Wang, C. Guo, "New evaluation method of optical detection accuracy for sheet metal forming size," Forg Stamp Tech, vol. A37, pp. 96-100, June 2012. 